\title{
Refeeding Syndrome in Adults Receiving Total Parenteral Nutrition: An Audit of Practice at a Tertiary UK Centre
}

Felipe Pantoja,,${ }^{1,2}$ Konstantinos C. Fragkos, ${ }^{1}$ Pinal. S. Patel, ${ }^{1}$ Niamh Keane, ${ }^{1}$ Mark A. Samaan, ${ }^{1}$ Ivana Barnova, ${ }^{1}$ Simona Di Caro, ${ }^{1}$ Shameer J. Mehta, ${ }^{1}$ Farooq Rahman ${ }^{1}$

${ }^{1}$ Intestinal Failure Service, Department of Gastroenterology, University College London Hospitals NHS Foundation Trust, 250 Euston Road, London NW1 2PG, United Kingdom

${ }^{2}$ Department of Clinical Nutrition, Clínica Las Condes, Santiago, Chile

Correspondence to:

Farooq Rahman

Intestinal Failure Service, Department of Gastroenterology

University College London Hospitals NHS Foundation Trust

250 Euston Road, London NW1 2PG, United Kingdom

e-mail: farooq.rahman@nhs.net

Tel. +44 (0) 20344 79311, Fax: +44 (0) 2034479217

Running head: Refeeding syndrome and parenteral nutrition

Abbreviations: BMI: body mass index, NCEPOD: National Confidential Enquiry Into Patient Outcome and Death, NICE: National Institute for Health and Care Excellence, RS: refeeding syndrome, TPN: total parenteral nutrition, UCLH: University College London Hospitals. 


\section{Abstract}

Background \& Aims: The key to preventing refeeding syndrome (RS) is identifying and appropriately managing patients at risk. We evaluated our clinical management of RS risk in patients starting total parenteral nutrition (TPN).

Methods: Patients commencing TPN at University College London Hospital between January and July 2015 were prospectively followed-up for 7-days. Eighty patients were risk assessed for RS and categorized into risk groups. High and low risk RS groups were compared focusing on the onset of biochemical features of RS (hypophosphatemia, hypokalaemia and hypomagnesemia) and initial clinical assessment. Statistical analysis was conducted using ttests and Mann-Whitney U tests.

Results: Sixty patients (75\%) were identified as high-risk for RS and received lower initial calories $(12.8 \mathrm{kcal} / \mathrm{kg} / \mathrm{day}, \mathrm{p}<0.05)$. All high-risk patients received a high potency vitamin preparation compared to $35 \%$ in the low risk group $(\mathrm{p}<0.05)$. Daily phosphate, magnesium and potassium plasma levels were monitored for seven days in $25 \%, 30 \%$ and $53.8 \%$ of patients, respectively. Hypophosphatemia developed in $30 \%$ and hypomagnesaemia and hypokalaemia in $27.5 \%$ of all patients. Approximately $84 \%$ of patients had one or more electrolyte abnormalities, which occurred more frequently in high-risk RS patients $(p<0.05)$. Low risk patients developed mild hypophosphatemia at a much lower percentage than high-risk RS (20\% vs $33.3 \%$, respectively).

Conclusion: A significant proportion of patients commencing TPN developed biochemical features of RS (but no more serious complications) despite nutritional assessment, treatment, and follow up in accordance with national recommendations. High vs low risk RS patients were more likely to have electrolyte abnormalities after receiving TPN regardless of preventative measures. Additional research is required to further optimise the initial nutritional approach to prevent RS in high-risk patients.

Keywords: total parenteral nutrition, refeeding syndrome, hypophosphatemia, hypokalaemia, hypomagnesaemia 


\section{Introduction}

Malnutrition is a common condition that contributes significantly to all cause morbidity and mortality. It remains largely unrecognized with reports showing that $70 \%$ of undernourished patients at time of admission are unidentified and not managed accordingly [1-3]. Reestablishing nutrition in a malnourished patient is associated with metabolic complications that are caused by the rapid change from a catabolic to an anabolic phase. Non-specific clinical signs, symptoms, and metabolic disorders, with hypophosphatemia as a hallmark feature, may follow this conversion [4]. This state is known as refeeding syndrome (RS) and is characterized by a rapid electrolytic intracellular shifts and metabolic disturbances produced after feeding a malnourished patient [5]. It is a preventable condition that can cause severe complications including multi-organ failure and death, and is often triggered within four to seven days of the supportive intervention [6]. RS is not only observed after long periods of starvation and considerable weight loss. Relatively healthy patients being partially or not fed for more than five to seven days, when exposed to acute metabolic stress such as surgery or trauma, can also be at risk of RS [7-11].

There is no consensus about the definition of RS. Its frequency has been described as anywhere from $0.43 \%$ in general wards to $34 \%$ in critical care patients $[12,13]$. Its hallmark feature is hypophosphatemia and it has been shown that all post-operative patients receiving total parenteral nutrition (TPN) without phosphate in the prescription developed hypophosphatemia [14]. Plasma levels of other electrolytes such as magnesium, potassium and sodium are also frequently affected (Supplementary Table 1). Furthermore, deficiencies of micronutrients such as B vitamins (particularly thiamine) play an important role [15]. Clinical features are the result of these imbalances and identifying high risk patients is mandatory for its prevention [7]. The National Institute for Health and Care Excellence (NICE) in the UK recommends a careful and thorough nutritional assessment before starting nutritional support to determine a patient's risk category. The calorie and nutrient content can then be individually adjusted in order to avoid the metabolic disturbances, reducing the risk of RS [16] (Supplementary Table 2).

TPN is a form of artificial nutrition support indicated in patients with intestinal failure. Patients receiving TPN are often at high risk of RS [17]. In 2010 a clinical audit performed by the National Confidential Enquiry into Patient Outcome and Death (NCEPOD) regarding TPN practice in the UK identified that $39 \%$ experienced metabolic complications; with hypophosphatemia, hypokalaemia and hypomagnesaemia the most common findings. However, these were felt to be avoidable in $49.4 \%$. RS occurred in $19 \%$ patients and in $1.5 \%$ patients the recommended prevention guidelines were not followed [18].

$\mathrm{RS}$ is a life-threatening condition that could result in death [19]. Despite this, there is a lack of knowledge of its occurrence and associated risk factors. Hence, the objective of this audit is to identify how RS risks are assessed and managed among patients commencing TPN prescribed by the Nutrition Support Team at University College London Hospital (UCLH), as well as examining the referral process and reasons for delays between referral, nutrition team assessment, and initiation of TPN. RS is examined under the prism of refeeding hypophosphatemia, hypomagnesaemia, and hypokalaemia. This could help provide useful information to improve RS awareness, prevention, and treatment.

\section{Methods}

\section{Settings}

UCLH is a large teaching hospital with 665 inpatient beds. All adult patients requiring TPN (except on the intensive care unit) are referred to the multidisciplinary nutrition support team consisting of doctors, nurse specialists, dietitians and pharmacists. A decision about 
commencing TPN is generally made after a full assessment (medical, nutritional, psychosocial), and discussion with the patient and primary team.

\section{Inclusion and Exclusion Criteria}

Inpatients over the age of age 18 years commencing TPN after referral to the nutrition support team between 1 January 2015 and 30 July 2015 were included in the audit. Patients who had received artificial nutritional support for at least a week before referral (i.e. commenced in the intensive care unit) were excluded. Patients were then prospectively followed up for sevendays. Regulatory approval was granted by the site institutional review board. Informed consent was not required for an audit of existing clinical practice. Individual patient data collected were anonymized. The principles of the Declaration of Helsinki were adhered to during design and analysis.

\section{Prescribing TPN at UCLH}

A nutritional assessment was conducted by the nutrition support team before prescribing TPN. The indication for TPN was confirmed and the inability to feed orally or enterally was explored. Nutritional status was assessed by the dietitians considering current weight, body mass index (BMI) (using most recent weight to the assessment), percentage of weight change in the past 3-6 months, clinical condition and underlying diseases by completing a standardized nutritional assessment form. With this information patients were classified as high-risk or low risk of RS according to NICE guidelines [16]. Patients were classified as high risk if they had one of the following criteria: a BMI lower than $16 \mathrm{~kg} / \mathrm{m}^{2}$; unintentional weight loss of $15 \%$ in the past three to six months; little or no nutrition for more than ten days; and low plasma levels of phosphate, potassium or magnesium before feeding starts. Furthermore patients were considered to be at high risk of RS if meeting two or more of the following criteria: BMI under $18.5 \mathrm{~kg} / \mathrm{m}^{2}$, unintentional weight loss of $10 \%$ in the last three to six months; unfed or partially fed for more than five days; and history of alcohol abuse or being in drugs such as chemotherapy, insulin, antacids or diuretics. In the opposite case they were considered low risk of RS [16].

Individual patient energy requirements were calculated using the Henry equation [20] for basal metabolic rate and adjusted for different activity and stress factors, as well as the maximum glucose oxidation rate, and nitrogen, lipid, and fluid requirements, using the standard recommendations from the British Dietetics Association. [21]. TPN scripts were individualized per patient with respect to composition of calories, macronutrients, electrolytes and trace elements. Patients were reviewed daily to three times per week by the nutrition support team upon starting TPN, depending on their risk of RS.

\section{Data Collection and Statistical Analysis}

Clinical and anthropometric data were collected (Supplementary Table 3). Blood samples for biochemical tests were obtained between 9 am and $12 \mathrm{pm}$, though not restricted at other times of the day as necessary. Data are presented as mean and standard deviation (SD) or median and range for continuous data and absolute and relative frequency for categorical data, respectively. Differences between groups were computed with t-tests for normally distributed data, MannWhitney $\mathrm{U}$ for non-normally distributed data, and chi-square test for categorical data with a pvalue $\leq 0.05$ indicating significance. For data analysis, IBM SPSS Statistics (Release 22.0.0. 2010, Chicago (IL), USA: SPSS, Inc., an IBM Company) was used.

\section{Results}

\section{Clinical and anthropometric characteristics according to RS risk and gender}

The sample included 80 patients $(51.2 \%$ women $)$ with mean age $55.8 \pm 17.3$ years. The mean BMI was $22.2 \pm 4.6 \mathrm{~kg} / \mathrm{m}^{2}$ and the median percentage of weight loss in the previous three months was $7.7 \%(-6.1,45.0) .75 \%$ of the patients were categorised as high risk of RS which 
was equally distributed among men and women. The calculated energy requirement was higher in males $(\mathrm{p}<0.05)$ with no difference at the initial energy infusion rate between genders. The most frequent indication for starting TPN was bowel obstruction caused by cancer $(33.8 \%)$, post-operative paralytic ileus (25\%), and surgical complications $(15 \%)$. The remaining indications for TPN included complicated Crohn's disease, bowel obstruction caused by peritoneal adhesions, graft versus host disease, pre-operative nutritional support, severe motility disorders, chronic radiation enteropathy and mucositis (Table 1).

Fifty-eight patients $(72.5 \%)$ completed at least 7 days on TPN while $93.8 \%$ received PN for more than 5 days. Of the 22 patients that did not reach 7 days the most common reason of stopping TPN was the resolution of post-operative paralytic ileus (40.9\%), death due to cancerrelated complications $(9.1 \%)$ and $50 \%$ were surgical patients that stopped TPN because the oral/enteral was re-established or were transferred to the intensive care unit after surgery. The most common electrolyte abnormalities during TPN were hypophosphatemia ( 24 cases, $30 \%$ ), and hypomagnesaemia (22 cases; $27.5 \%$ ) with no differences by gender. Hypokalaemia also occurred in 22 patients $(27.5 \%)$ and was more common in women by $29.6 \%(\mathrm{p}<0.05)$. When further stratified by RS risk group, women were still more prone to develop hypokalaemia $(33.3 \%, \mathrm{p}<0.05)$.

Sixty patients $(75 \%)$ of the sample were classified at being at high risk of RS. There were no differences between high and low risk of RS groups in age, gender, BMI, TPN indication, albumin, calculated calorie requirements and electrolyte deficiencies prior commencing TPN. The high risk of RS group had a greater weight loss percentage during a three month period before evaluation and remained on TPN longer compared to the low risk RS patients ( $p<0.05$ ) (Table 2). The initial TPN infusion rate was significantly lower in the high risk of RS group with a median of $12.8 \mathrm{kcal} / \mathrm{kg} /$ day $(8.9,18.9)$ compared to the low risk group [ $23.2 \mathrm{kcal} / \mathrm{kg} / \mathrm{day}$ $(10.8,33.9), \mathrm{p}<0.05]$. Moreover, the infusion rate was not related with the presence of hypophosphatemia, hypomagnesaemia or hypokalaemia in both RS risk groups. The percentage of the patients' daily energy requirement provided by TPN was lower amongst the high vs low RS group (42.2\% vs $87.7 \%, \mathrm{p}<0.05)$. The median time between the referral and the evaluation by the nutrition support team was 0 days $(0,3)$, and the median time between evaluation and commencement of TPN was 0 days $(0,7)$, with no differences between risk groups (Table 2). Forty-seven patients (58.8\%) were evaluated on the same day the referral was made and $98.8 \%$ within 24 hours. Only one case took more than one day to be evaluated and was assessed 72 hours after a referral received late on a Friday afternoon.

All high-risk patients received at least one infusion of a high potency multivitamin preparation (Pabrinex; Kyowa Kirin Ltd.) prior to commencing TPN while it was only received in $35 \%$ of the low risk group $(\mathrm{p}<0.05)$. Pabrinex was administered twice daily for 72 hours. Forty-five percent and $75 \%$ of the patients in the high and low risk groups commenced TPN on the day of the assessment. Overall 81.2\% started TPN within 24 hours of evaluation, without differences between risk groups. Patients who had central venous access at the time of the evaluation $(58 \%)$ started TPN within 24 hours more frequently than the rest, with a difference of $25.4 \%(\mathrm{p}<0.05)$.

The requested blood tests for each electrolyte were classified in four groups whether they were requested daily or there was one, two or three days or more without measurement during the TPN period. Phosphate was reviewed daily in 20 patients $(25 \%)$ while in $31.3 \%$ of the cases it was not measured for three or more days. Similarly, magnesium was requested every day in 24 patients $(30 \%)$ while in $38.8 \%$ of them it was not measured for three or more days. Potassium was checked daily in $53.8 \%$ of the sample, but in 6 patients it was not evaluated for three or more days. No differences were found between high and low risk of RS (Table 3). 
Table 1. Anthropometrical and clinical features of the sample categorized by gender.

\begin{tabular}{lccc}
\hline & Male $(\mathbf{n}=\mathbf{3 9})$ & Female $(\mathbf{n}=\mathbf{4 1})$ & Total $(\mathbf{n}=\mathbf{8 0})$ \\
\hline Age (years) & $58.1 \pm 17.1$ & $53.0 \pm 17.3$ & $55.8 \pm 17.3$ \\
BMI (kg/m $\mathbf{m}^{2}$ & $22.9 \pm 4.4$ & $21.4 \pm 4.6$ & $22.2 \pm 4.6$ \\
Weight Loss (\%) & $6.6(-4.1,45.1)$ & $9.7(-6.1,27.3)$ & $7.7(-6.1,45.0)$ \\
Albumin (g/L) & $29(19,50)$ & $29(18,43)$ & $29(18,50)$ \\
Energy Requirements (kcal) & $2081(1555,2680)^{*}$ & $1682(1340,2400)^{*}$ & $1836(1340,2680)$ \\
TPN starting infusion kcal/kg/day & $13.1(9.0,32.5)$ & $15.1(9.3,40.5)$ & $14.3(9.0,40.5)$ \\
Daily Requirements met (\%) & $42.9(31.7,104.0)$ & $44.6(19.7,106.1)$ & $43.9(19.7,106.1)$ \\
High-risk RS (\%) & $29(74.4 \%)$ & $31(75.6 \%)$ & $60(75 \%)$ \\
Highpotency Vitaminand Traceelementsinfused(\%) & $32(82 \%)$ & $35(85.5 \%)$ & $67(83.8 \%)$ \\
Hypophosphatemia During TPN (\%) & $10(25.6 \%)$ & $14(34.1 \%)$ & $24(30 \%)$ \\
Hypomagnesaemia During TPN (\%) & $10(25.6 \%)$ & $12(29.3 \%)$ & $22(27.5 \%)$ \\
Hypokalaemia During TPN (\%) & $6(15.4 \%)^{*}$ & $16(39 \%)^{*}$ & $22(27.5 \%)$ \\
\hline
\end{tabular}

Values present means \pm SD, median (ranges), $\mathrm{N}(\%) . * \mathrm{p}<0.05$, for differences between genders

Table 2. Anthropometric, clinical, biochemical and referral descriptives categorized by risk of RS before starting TPN.

\begin{tabular}{|c|c|c|c|}
\hline & High Risk RS $(n=60)$ & Low Risk RS $(\mathbf{n}=20)$ & Total $(n=80)$ \\
\hline Age (years) & $56.2 \pm 16.4$ & $54.5 \pm 20.3$ & $55.8 \pm 17.3$ \\
\hline BMI $\left(\mathrm{kg} / \mathrm{m}^{2}\right)$ & $21.7 \pm 4.6$ & $23.5 \pm 4.3$ & $22.2 \pm 4.6$ \\
\hline Weight Loss (\%) & $9.8(-6.1,45.0)^{\mathbb{I I}}$ & $2.3(0.0,21.1)^{\mathrm{TI}}$ & $7.7(-6.1,45.0)$ \\
\hline Albumin $(g / L)$ & $29(18,50)$ & $29(23,47)$ & $29(18,50)$ \\
\hline Energy Requirements (kcal) & $1817(1340,2449)$ & $1740(1471,2680)$ & $1836(1340,2680)$ \\
\hline TPN starting infusion $\mathrm{kcal} / \mathrm{kg} / \mathrm{day}$ & $12.8(8.9,18.9)^{\mathbb{I}}$ & $23.2(10.8,33.9)^{\mathrm{I}}$ & $14.3(9.0,40.5)$ \\
\hline Daily Requirements met $(\%)$ & $42.2(19.7,55.9)^{\mathbb{I}}$ & $87.7(38.9,106.1)^{\mathscr{T}}$ & $43.9(19.7,106.1)$ \\
\hline $\begin{array}{l}\text { High potency Vitamin and Trace } \\
\text { elements infused }(\%)\end{array}$ & $60(100 \%)^{\pi}$ & $7(35 \%)^{\mathbb{I}}$ & $67(83.8 \%)$ \\
\hline Hypophosphatemia Pre-TPN & $16(26.7 \%)$ & $3(15 \%)$ & $19(23.8 \%)$ \\
\hline Hypomagnesaemia Pre-TPN & $17(28.3 \%)$ & $14(20 \%)$ & $21(26.3 \%)$ \\
\hline Hypokalaemia Pre-TPN & $8(13.4 \%)$ & $1(5 \%)$ & $9(10.4 \%)$ \\
\hline Days on TPN & $12(3,68)^{\mathbb{I}}$ & $7(4,20)^{\mathbb{I}}$ & $11(3,68)$ \\
\hline Referral / Evaluation (Days) & $0(0,3)$ & $0(0,1)$ & $0(0,3)$ \\
\hline Evaluation/TPN starts (Days) & $1(0,7)$ & $0(0,3)$ & $0(0,7)$ \\
\hline \multicolumn{4}{|l|}{ Nutritional evaluation } \\
\hline Day of referral & $34(56.7 \%)$ & $13(65 \%)$ & $47(58.8 \%)$ \\
\hline $1^{\text {st }}$ day from referral & $25(41.7 \%)$ & $7(35 \%)$ & $32(40 \%)$ \\
\hline Within $1^{\text {st }}$ day & $59(98.4 \%)$ & $20(100 \%)$ & $79(98.8 \%)$ \\
\hline $\begin{array}{l}\text { Central Line on place at Evaluation } \\
(\%)\end{array}$ & $30(50 \%)^{\mathrm{Il}}$ & $13(65 \%)^{\mathbb{4}}$ & $43(53.8 \%)$ \\
\hline \multicolumn{4}{|l|}{ TPN started on: } \\
\hline Day of evaluation & $27(45 \%)$ & $14(70 \%)$ & $41(51.2 \%)$ \\
\hline $1^{\text {st }}$ day & $19(31.7 \%)$ & $5(25 \%)$ & $24(30 \%)$ \\
\hline Within $1^{\text {st }}$ day & $46(76.7 \%)$ & $19(95 \%)$ & $65(81.2 \%)$ \\
\hline
\end{tabular}

Values present means $\pm \mathrm{SD}$, median (ranges), $\mathrm{N}(\%)$. ${ }^{\mathrm{T}} \mathrm{p}<0.05$, for differences between high risk and low risk RS. 
Table 3. Biochemical measurements and responses during TPN.

\begin{tabular}{|c|c|c|c|}
\hline & High Risk RS $(n=60)$ & Low Risk RS $(n=20)$ & Total $(\mathbf{n}=\mathbf{8 0})$ \\
\hline \multicolumn{4}{|l|}{ Phosphate measurements during TPN } \\
\hline Daily & $17(28.3 \%)$ & $3(15 \%)$ & $20(25 \%)$ \\
\hline 1 day off & $16(26.7 \%)$ & $4(20 \%)$ & $20(25 \%)$ \\
\hline 2 days off & $11(18.3 \%)$ & $4(20 \%)$ & $15(18.8 \%)$ \\
\hline$\geq 3$ days off & $16(26.7 \%)$ & $9(45 \%)$ & $25(31.3 \%)$ \\
\hline \multicolumn{4}{|l|}{ Magnesium measurements during } \\
\hline \multicolumn{4}{|l|}{ TPN } \\
\hline Daily & $20(33.3 \%)$ & $4(20 \%)$ & $24(30 \%)$ \\
\hline 1 day off & $9(15 \%)$ & $2(10 \%)$ & $11(13.8 \%)$ \\
\hline 2 days off & $11(18.3 \%)$ & $3(15 \%)$ & $14(17.5 \%)$ \\
\hline$\geq 3$ days off & $20(33.3 \%)$ & $11(55 \%)$ & $31(38.8 \%)$ \\
\hline \multicolumn{4}{|l|}{ Potassium measurements during TPN } \\
\hline Daily & $32(53.3 \%)$ & $11(55 \%)$ & $43(53.8 \%)$ \\
\hline 1 day off & $11(18.3 \%)$ & $5(25 \%)$ & $16(20 \%)$ \\
\hline 2 days off & $12(20 \%)$ & $3(15 \%)$ & $15(18.8 \%)$ \\
\hline$\geq 3$ days off & $5(8.3 \%)$ & $1(5 \%)$ & $6(7.5 \%)$ \\
\hline \multicolumn{4}{|l|}{ Phosphate plasma levels } \\
\hline Normal / High (> 0.85 mmol/L) & $40(66.7 \%)$ & $16(80 \%)$ & $56(70 \%)$ \\
\hline Hypophosphatemia $(<0.85 \mathrm{mmol} / \mathrm{L})$ & $20(33.3 \%)$ & $4(20 \%)$ & $24(30 \%)$ \\
\hline Mild $(0.60-0.85 \mathrm{mmol} / \mathrm{L})$ & $12(20 \%)$ & $4(20 \%)$ & $16(20 \%)$ \\
\hline Moderate $(0.30-0.60 \mathrm{mmol} / \mathrm{L})$ & $7(11.7 \%)$ & -- & $7(8.8 \%)$ \\
\hline Severe $(<0.30 \mathrm{mmol} / \mathrm{L})$ & $1(1.7 \%)$ & -- & $1(1.2 \%)$ \\
\hline \multicolumn{4}{|l|}{ Magnesium plasma levels } \\
\hline Normal / High (>0.70 mmol/L) & $42(70 \%)$ & $16(80 \%)$ & $58(72.5 \%)$ \\
\hline Hypomagnesaemia $(<0.70 \mathrm{mmol} / \mathrm{L})$ & $18(30 \%)$ & $4(20 \%)$ & $22(27.5 \%)$ \\
\hline Mild/Moderate $(0.50-0.70 \mathrm{mmol} / \mathrm{L})$ & $17(28.3 \%)$ & $4(20 \%)$ & $21(26.3 \%)$ \\
\hline Severe $(<0.50 \mathrm{mmol} / \mathrm{L})$ & $1(1.7 \%)$ & -- & $1(1.2 \%)$ \\
\hline \multicolumn{4}{|l|}{ Potassium plasma levels } \\
\hline Normal / High (> $3.5 \mathrm{mmol} / \mathrm{L})$ & $41(68.3 \%)$ & $17(85 \%)$ & $58(72.5 \%)$ \\
\hline Hypokalaemia $(<3.5 \mathrm{mmol} / \mathrm{L})$ & $19(31.7 \%)$ & $3(15 \%)$ & $22(27.5 \%)$ \\
\hline Mild (3.0-3.5 mmol/L) & $14(23.3 \%)$ & $2(10 \%)$ & $16(20 \%)$ \\
\hline Moderate (2.5-3.0 mmol/L) & $4(6.7 \%)$ & $1(5 \%)$ & $5(6.3 \%)$ \\
\hline Severe $(<2.5 \mathrm{mmol} / \mathrm{L})$ & $1(1.7 \%)$ & -- & $1(1.2 \%)$ \\
\hline
\end{tabular}

Values present means \pm SD, median (ranges), $\mathrm{N}(\%) .{ }^{\text {I }} \mathrm{p}<0.05$, for differences between high risk and low risk RS.

\section{Metabolic derangements during TPN}

Twenty-four patients (30\%) developed hypophosphatemia while receiving TPN, 20 of these patients were at high risk of RS. The cut-offs of severity for electrolyte disturbances are shown in Supplementary Table 1 . Seven cases of moderate $(0.30-0.60 \mathrm{mmol} / \mathrm{L})$ and one case of severe (<30 mmol/L) hypophosphatemia arose within the high-risk group, compared with four cases of mild hypophosphatemia in the low risk group. No significant differences were found by RS risk group (Figure 1). Hypomagnesaemia and hypokalaemia had the same frequency of occurrence with 22 cases (27.5\%) of which 18 (30\%) and $19(31.7 \%)$ cases were at high risk of RS respectively. The severity and the distribution among groups showed no statistical differences (Table 3). In the high-risk RS group, the presence of hypomagnesaemia at the initial assessment was associated with hypomagnesaemia during TPN, despite being adequately replaced. $(57.6 \%, \mathrm{p}<0.05)$.

In a case-by-case analysis trying to identify the frequency of isolated electrolyte disturbances and their combinations, hypophosphatemia was encountered as the only derangement in 9 $(11.3 \%)$, hypomagnesaemia in $8(10 \%)$ and hypokalaemia in $6(7.5 \%)$ patients. The three conditions together occurred in 7 patients $(8.8 \%)$, who were all at high risk of RS (Figure 2A). In total 42 patients $(52.5 \%)$ developed at least one plasma electrolyte deficiency after commencing TPN, of which 35 patients were considered to be at high risk of RS.

Hypermagnesemia was the most common electrolyte disorder during TPN accounting for 27 
cases (33.8\%). Nine of them had high levels for more than 2 days and 12 fluctuated between high and low plasma levels. Hyperphosphatemia was seen in 24 patients $(30 \%)$ and persisted for more than 2 days in 10 patients, while six showed high and low levels during TPN. Similarly, hyperkalaemia arose in $21.3 \%$ of the sample and six of them had high and low levels (Figure 2B). No differences existed between high and low risk of RS.

With regards to electrolyte disturbances, only $13(16.2 \%)$ treated patients maintained normal plasma levels of phosphate, magnesium and potassium whilst receiving TPN. Of the $67(83.8 \%)$ patients that presented with either high or low levels of at least one of the electrolytes, $n=54$ were at high risk of RS. Therefore, patients at high risk had 25\% ( $\mathrm{p}<0.05)$ more electrolyte abnormalities than those classified as low risk of RS (Figure 2C).

In $>70 \%$ of the cases, hypophosphatemia, hypomagnesaemia and hypokalaemia occurred within two days of commencing TPN. Nine cases (37.5\%) of hypophosphatemia occurred on the first day of TPN and $8(33.3 \%)$ on the second. Hypokalaemia showed a similar trend with $8(36.4 \%)$ occurring on the first day and $7(31.8 \%)$ on day 2 . Hypomagnesaemia was seen in $11(50 \%)$ patients on the first day and was significantly associated with the presence of hypomagnesaemia at the time of evaluation $(32.7 \%, \mathrm{p}<0.05)$ (Figure 2D).

Figure 1. Flow chart summarizing the occurrence of hypophosphatemia and it severity after starting PN categorized by risk RS groups. \% of RS group risk. R-F = Refeeding, HP = Hypophosphatemia.

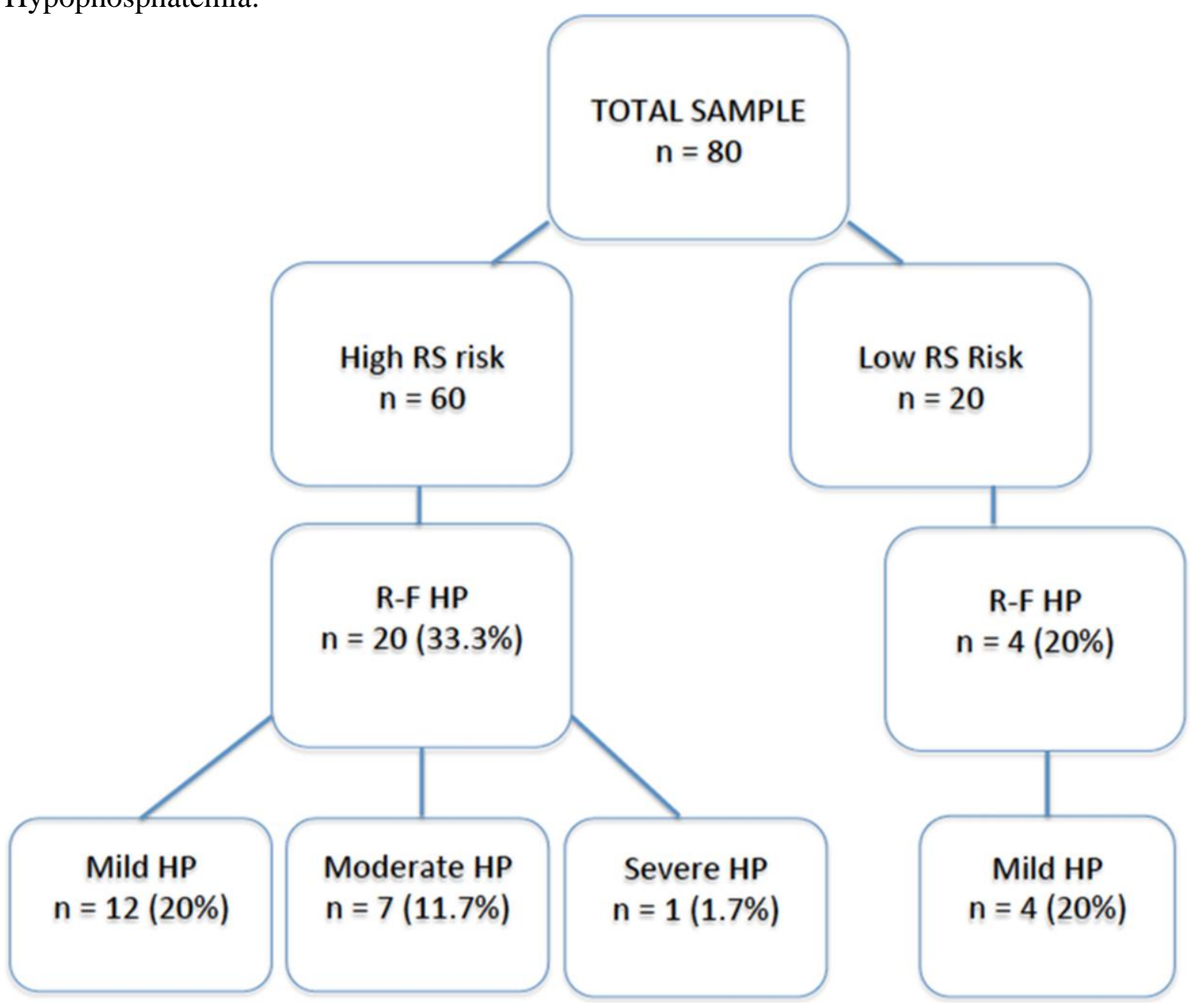


Figure 2. A. Frequency of clinical cases presenting low plasma levels of phosphate, magnesium, potassium, individually and in combination $(n=42)$. B. Frequency of cases showing normal, low, and high electrolyte plasma levels during TPN, individually and in combination. Figure 2B shows the number of cases categorized by normal, low, and high plasma levels of phosphate, magnesium and potassium. The 24 cases represented on the 'High and Low levels' category are also included in the values presented for the previous categories. C. Frequency of patients presenting at least one of the electrolytes, phosphate, magnesium or potassium out of the normal reference range during TPN by groups of risk of RS, * $\mathrm{p}<0.05$. D. Graphic representation showing the onset day of hypophosphatemia, hypomagnesaemia and hypokalaemia. *Hypomagnesaemia prior to starting TPN was associated with hypomagnesaemia during the first day of TPN $(32.7 \%, \mathrm{p}<0.05)$.

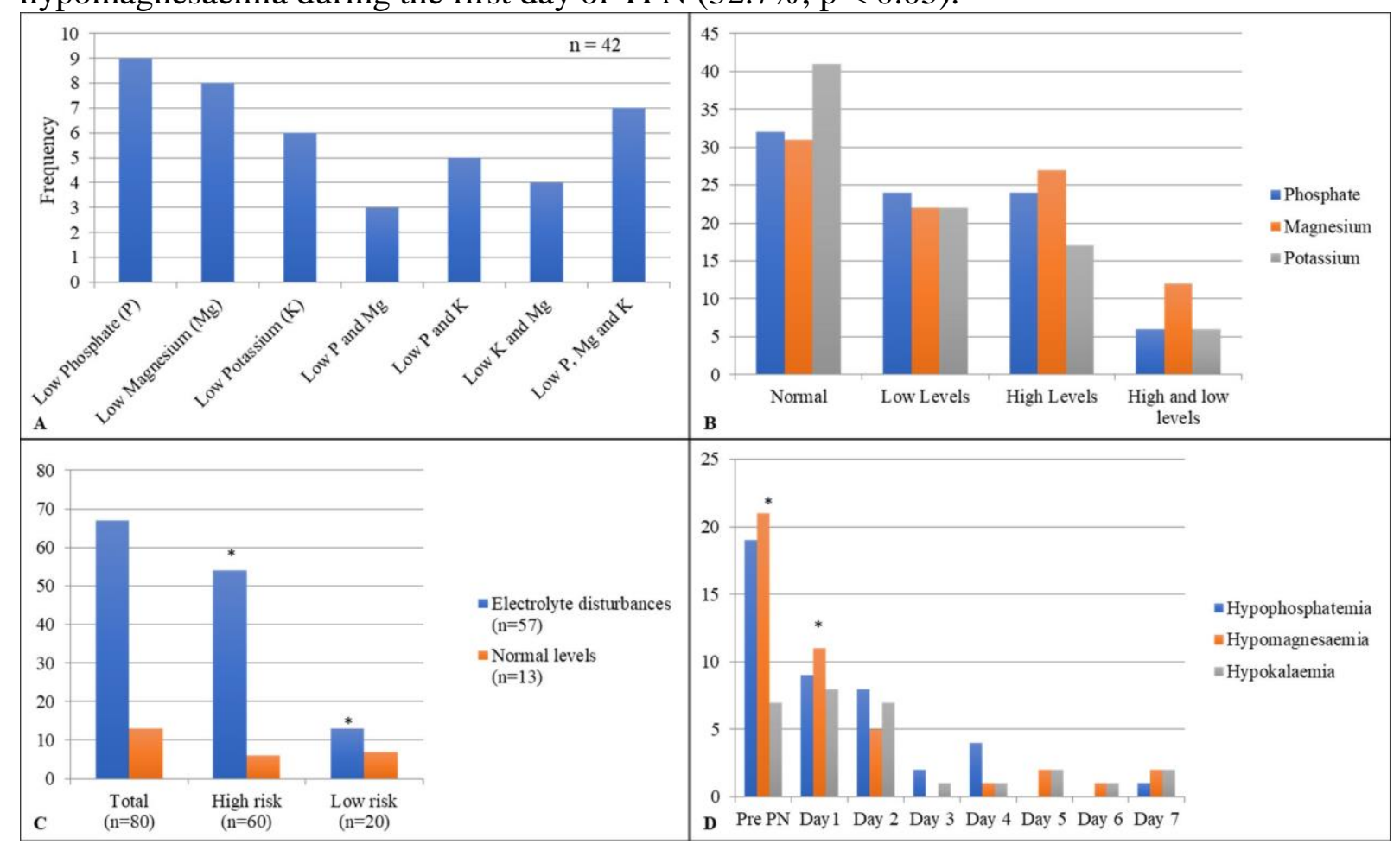

\section{Discussion and Conclusion}

Our results show that every patient referred to the nutrition support team for TPN received a thorough nutritional assessment at the time of evaluation, including biochemical status, and were risk stratified for RS [16]. This contrasts favourably with the results of the NCEPOD report (2010), which found that only $54.1 \%$ of patients had a proper nutritional evaluation before starting TPN. Most of our sample (75\% patients) were classified at high risk of RS. The only anthropometrical difference identified between high and low risk RS groups was percentage weight loss prior to commencing TPN (9.8\%), one of the important risk factors of RS defined by NICE guidelines [16]. Accordingly, high and low risk of RS groups were treated differently. Every patient considered to be at high risk of RS received an infusion of a high potency vitamin preparation [16] compared to only $35 \%$ in the low risk group $(65 \%, \mathrm{p}<0.05)$. The recommendations of cautious initial nutritional support for patients at high risk of RS have been chronicled since 1981, when a death was reported due to RS [19]. Subsequently, a cautious rate of $20 \mathrm{kcal} / \mathrm{kg} /$ day was suggested, increasing the calorie infusion slowly to reach full requirements by the $7^{\text {th }}$ day [22]. NICE later suggested an initial $10 \mathrm{kcal} / \mathrm{kg} / \mathrm{day}$ TPN infusion rate for patients at high risk of RS [16]. In the studied sample, the initial TPN infusion rate was significantly lower among the high-risk group with a median of $12.8 \mathrm{kcal} / \mathrm{kg} / \mathrm{day}$, 
compared to $23.2 \mathrm{kcal} / \mathrm{kg} /$ day in the low risk group $(\mathrm{p}<0.05)$. Patients at high risk of $\mathrm{RS}$ received an initial calorie content with a median of $42.2 \%$ of their daily energy requirements compared to $87.7 \%$ among the low risk of RS group ( $p<0.05)$. These findings are in accordance with the aforementioned cautious approach to initial nutritional support and highlights the importance of expert nutrition support teams treating patients according to their initial RS risk assessment. The initial TPN infusion rate in our sample surpassed the figures suggested by NICE guidelines [16]. Nevertheless, this threshold is an arbitrary amount set by a group of experts with no randomized clinical trial evidence to support it. Additionally, in our sample, amongst the high risk of RS group ( $n=60)$, no differences in electrolyte shifts were seen when analysing by amount of TPN infused (range: 8.9 to $18.9 \mathrm{kcal} / \mathrm{kg} / \mathrm{day}$ ). Considering the limitations of this study, these findings suggest that a limit of $10 \mathrm{kcal} / \mathrm{kg} / \mathrm{day}$ as an initial TPN infusion rate could end in patients being underfed without preventing the RS onset and should be revisited.

The second important requirement in recognizing and treating early features of RS in a timely manner is to maintain strict daily biochemical vigilance during the first week of nutrition support $[4,22,23]$. In our sample, we observed that $25 \%$ and $30 \%$ of patients had plasma phosphate and magnesium levels checked daily during the first week of TPN, respectively, while in $31.3 \%$ and $38.8 \%$ of cases, levels were not measured for three or more days. These findings are in concordance with the NCEPOD report (2010) where regular biochemistry review was suboptimal. Patients starting TPN remained under the care of their primary medical/surgical team with regular review by the nutrition support team and advice for daily biochemical review. There were multiple reasons for irregular biochemical review after initiating TPN. For example, patients declining blood tests or not being present at the bedside at the time when the phlebotomist attended. Nonetheless, potassium levels were available every day in $53.8 \%$ patients of the sample and only $7.5 \%$ did not have test results available for three or more days. This suggests that serum phosphate and magnesium could have been measured at least at the frequency of serum potassium, and that they were often not requested on days where other blood tests were taken. Identification of biochemical deficiencies during the first week of nutritional support is critical as RS onset is more frequently encountered between the second and fourth day [24]. Therefore, in agreement with the $49.4 \%$ of avoidable metabolic complications found by the NCEPOD report (2010) [18], daily biochemistry review is vital for the recognition of RS features, as early treatment of hypophosphatemia, can prevent more serious metabolic disorders and clinical complications. This organizational issue should be evaluated to allow the nutrition support team to have all the resources required to delivery evidence-based best practice.

When analysing biochemistry test results, focusing particularly on serum phosphate, magnesium and potassium levels, no significant differences were found between RS risk groups either prior to or after commencing TPN. Nineteen (23.8\%) patients had hypophosphatemia at the time of evaluation and 24 patients (30\%) developed hypophosphatemia while receiving TPN. Twenty $(33 \%)$ of them were at high risk of RS. These findings are consistent with other studies showing that $27.5 \%$ to $42 \%$ of high-risk of RS patients developed hypophosphatemia during the first week of nutritional support $[25,26]$. No association was found between groups of high and low risk of RS and hypophosphatemia during TPN.

Hypomagnesaemia was present in $21(26.3 \%)$ patients prior to commencement of TPN and in 22 cases $(27.5 \%)$ during the supportive nutrition phase. Eighteen $(30 \%)$ were at high risk of RS. No association was found between low serum magnesium levels before starting TPN and the incidence of hypophosphatemia during nutrition support, contrasting with the conclusions of a recent prospective cohort study establishing hypomagnesaemia as a predictor of occurrence of RS [27]. However, hypomagnesaemia prior to the commencement of TPN was associated with hypomagnesaemia during the supportive phase among the high-risk RS group despite 
being replaced according to guidelines $(57.6 \% \mathrm{p}<0.05)$. Hypokalaemia was present in 9 $(10.4 \%)$ patients before TPN initiation and was found to be more frequent amongst women at high risk of RS $(33.3 \%, \mathrm{p}<0.05)$. This preponderance was also shown in a retrospective study of a large cohort of hospitalized patients where female gender was established to be a risk factor of developing hypokalaemia [28], possibly due to a lower amount of total exchangeable potassium due to gender differences in body composition [29].

No consensus definition for the diagnosis of RS has been established to date. Every publication reviewed consistently establishes the presence of hypophosphatemia as the hallmark of RS. Nonetheless RS is a complex clinical scenario accompanied by several symptoms and signs in addition to hypophosphatemia [30]. In our sample, no episodes of severe RS occurred, but hypophosphatemia was observed in $33.3 \%$ of the patients at high risk of RS during TPN. The term 'refeeding hypophosphatemia' is used in the literature by different authors and may be more applicable to these results $[5,31]$. Most patients from the sample $(52.5 \%)$ developed at least one low serum level of the three electrolytes in question, and of those who had hypophosphatemia (24), 62.5\% had at least one more low plasma electrolyte level. In a systematic review of RS cases, Skipper [31] revealed similar trends, finding that the majority of patients categorized as having RS by hypophosphatemia also presented with other laboratory abnormalities. Hypermagnesaemia was the most frequent electrolyte disorder during TPN accounting for 27 cases $(33.8 \%)$.

Finally, the onset of hypophosphatemia after commencing TPN was more commonly seen on the first and second day with a second peak at day four. This corroborates earlier findings reporting the onset of RS between the second and the fifth day after starting the nutrition support [24, 31], again emphasising the need of close biochemical monitoring during the first week of refeeding.

In conclusion, this audit showed that the UCLH nutrition team appropriately pre-assess and risk stratify all patients referred for TPN. Furthermore, they adhere to NICE Guidelines to manage patients according to their risk of RS. Metabolic disturbances are seen during the nutritional support, despite following expert recommendations, emphasizing the need for more studies in the field to complete the understanding of this physiological enigma. Ensuring more regular biochemical monitoring was highlighted as an area of clinical practice to improve.

\section{Funding Sources}

This research did not receive any specific grant from funding agencies in the public, commercial, or not-for-profit sectors.

\section{Conflicts of Interest}

None to declare.

\section{Author contributions}

FP, PSP, NK, and KCF collected and analysed the data and prepared the manuscript; MAS and IB helped with data collection; SJM, SDC, and FR conceived and supervised the audit and edited the manuscript. 


\section{Supplementary Materials}

Supplementary Table 1. Electrolyte imbalances during RS, clinical manifestations and recommended treatments $[6,16,21,32]$.

\begin{tabular}{|c|c|c|}
\hline Electrolytes & Treatment & $\begin{array}{l}\text { Clinical manifestations in severe } \\
\text { deficiency }\end{array}$ \\
\hline \multicolumn{3}{|l|}{ Phosphate } \\
\hline $\begin{array}{l}\text { Normal (0.85-1.45 } \\
\text { mmol/L) } \\
\text { (Maintenance dosage) }\end{array}$ & $\begin{array}{l}0.3-0.6 \mathrm{mmol} / \mathrm{kg} / \mathrm{day} \\
\text { orally }\end{array}$ & \\
\hline \multicolumn{3}{|l|}{ Hypophosphatemia } \\
\hline Mild $(0.60-0.85 \mathrm{mmol} / \mathrm{L})$ & $\begin{array}{l}0.3-0.6 \mathrm{mmol} / \mathrm{kg} / \mathrm{day} \\
\text { orally }\end{array}$ & \multirow{3}{*}{$\begin{array}{l}\text { Weakness, paraesthesia, acute } \\
\text { encephalopathy, muscular weakness, } \\
\text { myalgia, rhabdomyolysis, decreased } \\
\text { cardiac contractility, cardiomyopathy, } \\
\text { platelets and leukocytes dysfunction, } \\
\text { thrombocytopenia, haemolysis, reduced } \\
\text { erythrocyte 2,3-diphosphoglycerate, } \\
\text { reduced ATP, impaired respiratory muscle } \\
\text { function resulting in respiratory failure or } \\
\text { ventilator dependency, osteomalacia, } \\
\text { acute tubular necrosis, tubular defects }\end{array}$} \\
\hline $\begin{array}{l}\text { Moderate }(0.30-0.60 \\
\mathrm{mmol} / \mathrm{L})\end{array}$ & $\begin{array}{l}9 \text { mmol infused into } \\
\text { peripheral vein over } 12 \\
\text { hours }\end{array}$ & \\
\hline $\operatorname{Severe}(<0.30 \mathrm{mmol} / \mathrm{L})$ & $\begin{array}{l}18 \text { mmol infused into } \\
\text { peripheral vein over } 12 \\
\text { hours }\end{array}$ & \\
\hline \multicolumn{3}{|l|}{ Magnesium } \\
\hline $\begin{array}{l}\text { Normal }(0.70-0.95 \\
\text { mmol/L) } \\
\text { (Maintenance dosage) }\end{array}$ & $\begin{array}{l}0.2 \mathrm{mmol} / \mathrm{kg} / \mathrm{day} \\
\text { intravenously (or } 0.4 \\
\mathrm{mmol} / \mathrm{kg} / \mathrm{day} \text { orally) }\end{array}$ & \\
\hline \multicolumn{3}{|l|}{ Hypomagnesaemia } \\
\hline $\begin{array}{l}\text { Mild to moderate } \\
(0.50-0.70 \mathrm{mmol} / \mathrm{L})\end{array}$ & $\begin{array}{l}0.5 \mathrm{mmol} / \mathrm{kg} / \text { day over } \\
\text { the first } 24 \mathrm{~h} \text {, then } 0.25 \\
\mathrm{mmol} / \mathrm{kg} / \mathrm{day} \text { over the } \\
\text { next } 5 \text { days }\end{array}$ & \multirow{2}{*}{$\begin{array}{l}\text { Tetany, paraesthesia, seizures, ataxia, } \\
\text { tremor, weakness, arrhythmias (e.g. } \\
\text { torsade de pointes), hypertension, } \\
\text { anorexia, abdominal pain, hypokalaemia, } \\
\text { hypocalcaemia }\end{array}$} \\
\hline Severe $(<0.50 \mathrm{mmol} / \mathrm{L})$ & $\begin{array}{l}24 \mathrm{mmol} \text { in } 6 \text { hours, then } \\
0.25 \mathrm{mmol} / \mathrm{kg} / \text { day over } \\
\text { the next } 5 \text { days }\end{array}$ & \\
\hline \multicolumn{3}{|l|}{ Potassium } \\
\hline $\begin{array}{l}\text { Normal }(3.5-5.1 \mathrm{mmol} / \mathrm{L}) \\
\text { (Maintenance dosage) }\end{array}$ & $2-4 \mathrm{mmol} / \mathrm{kg} / \mathrm{day}$ & \\
\hline \multicolumn{3}{|c|}{ Hypokalaemia (reduction of $0.3 \mathrm{mmol} / \mathrm{L}$ in plasma suggests $100 \mathrm{mmol}$ body deficit) } \\
\hline $\begin{array}{l}\text { Moderate }(2.5-3.0 \\
\mathrm{mmol} / \mathrm{L})\end{array}$ & $\begin{array}{l}\text { Correct accordingly } \\
\text { Maximum peripheral } \\
\text { infusion rate } 20 \\
\text { mmol/hour }\end{array}$ & \multirow{2}{*}{$\begin{array}{l}\text { Paralysis, paraesthesia, rhabdomyolysis, } \\
\text { respiratory depression, weakness, } \\
\text { arrhythmias, hypotension, digoxin } \\
\text { toxicity, cardiac arrest, constipation, } \\
\text { paralytic ileus, decreased urinary } \\
\text { concentrating ability, metabolic alkalosis, } \\
\text { glucose intolerance }\end{array}$} \\
\hline Severe $(<2.5 \mathrm{mmol} / \mathrm{L})$ & $\begin{array}{l}\text { Consider correction via } \\
\text { central line }\end{array}$ & \\
\hline
\end{tabular}


Supplementary Table 2. NICE criteria for patients with high risk of developing RS and the recommended initial nutritional support [16].

\begin{tabular}{|c|c|}
\hline $\begin{array}{l}\text { NICE Guidelines criteria for high risk of } \\
\text { RS }\end{array}$ & Recommended initial nutritional support \\
\hline $\begin{array}{l}\text { Having } 1 \text { of the following conditions: } \\
\text { - BMI }<16 \mathrm{~kg} / \mathrm{m}^{2} \\
\text { - Unexpected weight loss greater than } 15 \% \\
\text { within the last } 3-6 \text { months } \\
\text { - Poor or nil nutrition for more than } 10 \text { days } \\
\text { - Hypokalaemia, hypophosphatemia or } \\
\text { hypomagnesaemia prior to feeding. }\end{array}$ & $\begin{array}{l}\text { 1. Before starting and daily for the first } 10 \text { days: } \\
\text { - Thiamine } 200-300 \mathrm{mg} \text { and high potency vitamin } \\
\text { B complex } 3 \text { times daily per oral route } \\
\qquad \text { Or } \\
\text { - Parenteral B complex including thiamine } 100 \\
\text { mg and trace element }\end{array}$ \\
\hline $\begin{array}{l}2 \text { or more of the following: } \\
\text { - BMI }<18.5 \mathrm{~kg} / \mathrm{m}^{2}\end{array}$ & $\begin{array}{l}\text { 2. Start nutrition at a maximum of } 10 \mathrm{kcal} / \mathrm{kg} / \mathrm{day} \text {, } \\
\text { slowly increase to meet full needs by } 4-7 \text { days. }\end{array}$ \\
\hline $\begin{array}{l}\text { - Unexpected weight loss greater than } 10 \% \\
\text { within the last 3-6 months } \\
\text { - Poor or nil nutrition for more than } 5 \text { days } \\
\text { - History of alcohol abuse or drugs including } \\
\text { insulin, chemotherapy, antacids or diuretics. }\end{array}$ & $\begin{array}{l}\text { 3. If Phosphate, Potassium, and Magnesium are in } \\
\text { normal range, provide maintenance dosage if not } \\
\text { replace without dallying the feed. }\end{array}$ \\
\hline $\begin{array}{l}\text { In extremely emaciated patients with } \mathrm{BMI}<14 \\
\mathrm{~kg} / \mathrm{m}^{2} \text { or nil oral intake }>15 \text { days }\end{array}$ & $\begin{array}{l}\text { - Start at } 5 \mathrm{kcal} / \mathrm{kg} / \mathrm{day} \\
\text { - Cardiac monitoring }\end{array}$ \\
\hline
\end{tabular}

Supplementary Table 3. Data collection variables.

\begin{tabular}{|c|c|}
\hline $\begin{array}{l}\text { Referral } \\
\text { details }\end{array}$ & Date of referral, reason for referral, referring speciality \\
\hline Medical & $\begin{array}{l}\text { Past medical history, recent and forthcoming surgeries, nausea, vomiting, } \\
\text { faecal output (bowel frequency, stoma output, fistula output) }\end{array}$ \\
\hline Nutrition & $\begin{array}{l}\text { Height, weight, BMI, \% weight loss } \\
\text { Estimated oral intake } \\
\text { Estimated enteral intake (if applicable) } \\
\text { Number of days nil nutrition } \\
\text { Estimated nutritional requirements (energy, nitrogen, lipid, glucose, fluid) } \\
\text { Previously on PN }\end{array}$ \\
\hline Medications & Prescription of B vitamins, IV fluids \\
\hline Biochemistry & $\begin{array}{l}\text { Sodium, potassium, magnesium, calcium, phosphate, magnesium, } \\
\text { albumin, c-reactive protein (pre PN and daily for } 7 \text { days on commencing } \\
\text { PN) }\end{array}$ \\
\hline
\end{tabular}




\section{References}

[1] McWhirter JP, Pennington CR. Incidence and recognition of malnutrition in hospital. BMJ. 1994;308:945-8, doi:10.1136/bmj.308.6934.945.

[2] Barker LA, Gout BS, Crowe TC. Hospital Malnutrition: Prevalence, Identification and Impact on Patients and the Healthcare System. Int J Environ Res Public Health. 2011;8:51427, doi:10.3390/ijerph8020514.

[3] Kelly IE, Tessier S, Cahill A, Morris SE, Crumley A, McLaughlin D, et al. Still hungry in hospital: identifying malnutrition in acute hospital admissions. QJM. 2000;93:93-8, doi:10.1093/qjmed/93.2.93.

[4] Khan LU, Ahmed J, Khan S, Macfie J. Refeeding syndrome: a literature review. Gastroenterol Res Pract. 2011;2011, doi:10.1155/2011/410971.

[5] Zeki S, Culkin A, Gabe SM, Nightingale JM. Refeeding hypophosphataemia is more common in enteral than parenteral feeding in adult in patients. Clin Nutr. 2011;30:365-8, doi:10.1016/j.clnu.2010.12.001.

[6] Crook MA, Hally V, Panteli JV. The importance of the refeeding syndrome. Nutrition. 2001;17:632-7, doi:10.1016/S0899-9007(01)00542-1.

[7] Mehanna HM, Moledina J, Travis J. Refeeding syndrome: what it is, and how to prevent and treat it. BMJ. 2008;336:1495-8, doi:10.1136/bmj.a301.

[8] Olthof LE, Koekkoek W, van Setten C, Kars JCN, van Blokland D, van Zanten ARH. Impact of caloric intake in critically ill patients with, and without, refeeding syndrome: A retrospective study. Clin Nutr. 2017:in press, doi:10.1016/j.clnu.2017.08.001.

[9] Owers EL, Reeves AI, Ko SY, Ellis AK, Huxtable SL, Noble SA, et al. Rates of adult acute inpatients documented as at risk of refeeding syndrome by dietitians. Clin Nutr.

2015;34:134-9, doi:10.1016/j.clnu.2014.02.003.

[10] Pourhassan M, Cuvelier I, Gehrke I, Marburger C, Modreker MK, Volkert D, et al. Risk factors of refeeding syndrome in malnourished older hospitalized patients. Clin Nutr. 2017:in press, doi:10.1016/j.clnu.2017.06.008.

[11] Rigaud D, Boulier A, Tallonneau I, Brindisi MC, Rozen R. Body fluid retention and body weight change in anorexia nervosa patients during refeeding. Clin Nutr. 2010;29:74955, doi:10.1016/j.clnu.2010.05.007.

[12] Camp MA, Allon M. Severe hypophosphatemia in hospitalized patients. Miner Electrolyte Metab. 1990;16:365-8

[13] Marik PE, Bedigian MK. Refeeding hypophosphatemia in critically ill patients in an intensive care unit. A prospective study. Arch Surg. 1996;131:1043-7,

doi:10.1001/archsurg.1996.01430220037007.

[14] Martinez MJ, Martinez MA, Montero M, Campelo E, Castro I, Inaraja MT.

Hypophosphatemia in postoperative patients with total parenteral nutrition: influence of nutritional support teams. Nutr Hosp. 2006;21:657-60

[15] Palesty JA, Dudrick SJ. The goldilocks paradigm of starvation and refeeding. Nutr Clin Pract. 2006;21:147-54, doi:10.1177/0115426506021002147.

[16] National Institute for Clinical Excellence GBN. Nutrition Support for Adults. Clinical Guideline CG32. 2006. p. 1-176.

[17] Walmsley RS. Refeeding syndrome: screening, incidence, and treatment during parenteral nutrition. J Gastroenterol Hepatol. 2013;28 Suppl 4:113-7, doi:10.1111/jgh.12345. [18] Stewart JAD, National Confidential Enquiry into Patient Outcome and Death. A mixed bag : an enquiry into the care of hospital patients receiving parenteral nutrition. London: National Confidential Enquiry into Patient Outcome and Death; 2010. 
[19] Weinsier RL, Krumdieck CL. Death resulting from overzealous total parenteral nutrition: the refeeding syndrome revisited. Am J Clin Nutr. 1981;34:393-9, doi:10.1093/ajen/34.3.393.

[20] Henry CJ. Basal metabolic rate studies in humans: measurement and development of new equations. Public Health Nutr. 2005;8:1133-52, doi:10.1079/PHN2005801.

[21] Nixon AM, Birchonough L. Refeeding Syndrome. In: Todorovic VE, Micklewright A, editors. A Pocket Guide To Clinical Nutrition: PEN Group of the British Dietetic Association; 2011.

[22] Solomon SM, Kirby DF. The refeeding syndrome: a review. JPEN J Parenter Enteral Nutr. 1990;14:90-7, doi:10.1177/014860719001400190.

[23] Stanga Z, Brunner A, Leuenberger M, Grimble RF, Shenkin A, Allison SP, et al. Nutrition in clinical practice-the refeeding syndrome: illustrative cases and guidelines for prevention and treatment. Eur J Clin Nutr. 2008;62:687-94, doi:10.1038/sj.ejcn.1602854.

[24] Adkins SM. Recognizing and preventing refeeding syndrome. Dimens Crit Care Nurs. 2009;28:53-8; quiz 9-60, doi:10.1097/DCC.0b013e318195d3e0.

[25] Ornstein RM, Golden NH, Jacobson MS, Shenker IR. Hypophosphatemia during nutritional rehabilitation in anorexia nervosa: implications for refeeding and monitoring. $\mathrm{J}$ Adolesc Health. 2003;32:83-8, doi:10.1016/S1054-139X(02)00456-1.

[26] Thompson JS, Hodges RE. Preventing hypophosphatemia during total parenteral nutrition. JPEN J Parenter Enteral Nutr. 1984;8:137-9, doi:10.1177/0148607184008002137.

[27] Rio A, Whelan K, Goff L, Reidlinger DP, Smeeton N. Occurrence of refeeding syndrome in adults started on artificial nutrition support: prospective cohort study. BMJ Open. 2013;3, doi:10.1136/bmjopen-2012-002173.

[28] Paice BJ, Paterson KR, Onyanga-Omara F, Donnelly T, Gray JM, Lawson DH. Record linkage study of hypokalaemia in hospitalized patients. Postgrad Med J. 1986;62:187-91, doi:10.1136/pgmj.62.725.187.

[29] Kleinfeld M, Borra S, Gavani S, Corcoran A. Hypokalemia: are elderly females more vulnerable? J Natl Med Assoc. 1993;85:861-4

[30] Crook MA. Refeeding syndrome: problems with definition and management. Nutrition. 2014;30:1448-55, doi:10.1016/j.nut.2014.03.026.

[31] Skipper A. Refeeding syndrome or refeeding hypophosphatemia: a systematic review of cases. Nutr Clin Pract. 2012;27:34-40, doi:10.1177/0884533611427916.

[32] Ahmed S, Travis J, Mehanna H. Re-feeding syndrome in head and neck--prevention and management. Oral Oncol. 2011;47:792-6, doi:10.1016/j.oraloncology.2010.06.009. 